\title{
Multi-objective Optimization Model of Multi-modal Transport Based on Regional Sustainability Indicators
}

\author{
Shengjiao Yang ${ }^{1}$, Zuoling Song ${ }^{1, a}$ \\ 1 School of Transportation, Shandong University of Science and Technology, 266590 Qingdao, China
}

\begin{abstract}
With the development of "One Belt, One Road" initiative and free trade area, the volume of cross-border international logistics involving multiple modes of transport has surged. Meanwhile, the proportion of using integrated transportation system in domestic trunk transport has increased. Multi-modal transport (MMT) based on green transport can realize intensive utilization of transport capacity resources, and implement sustainable transport management with three bottom lines of economic, environmental and social aspects. In this paper, the carbon emission index and regional transportation infrastructure utilization index are introduced to construct a multiobjective optimization model with sustainable goals of environmental protection, cost saving and social contribution. The poly-population genetic algorithm (PPGA) is used to overcome the limitation of the traditional genetic algorithm running to the local optimum. The model proposed by this paper quantifies environmental and social indicators, balances comprehensive performance of environment, economy and society, and provides quantitative decision making support for carriers, international freight forwarder or third party logistics to carry out green MMT.
\end{abstract}

Keywords: Sustainable transportation, Multi-modal transport, Multi-objective optimization, Poly-population genetic algorithm.

\section{Introduction}

Development strategies such as "One Belt and One Road" and free trade area planning in China have increased the volume of international trade and freight. Cross-border multi-modal transport is the main form of international logistics. The increasing importance of multimodal transportation makes it consider the efficiency of the whole process and propose a model to quantify the process of transit consolidation (B. Lv etc., 2019; Y. Wang and G. Yeo, 2016) $)^{[1-2]}$.

Environment-friendly multi-modal transport breaks down trade barriers, green barriers or blue barriers. In order to build the environmental symbiosis transportation system, the domestic long-distance trunk transportation has more and more used MMT and other comprehensive transportation modes. Various methods such as biobjective mixed integer nonlinear programming model, goal programming, mainly consider total transportationrelated costs and total carbon emissions (M. Salehi etc., 2017; B.Q. Lin and N. I. Benjamin, 2017) ${ }^{[3-4]}$, while seldom relate social factors and other comprehensive factors.

MMT based on green transport is an important measure to improve cost reduction, efficiency and the service satisfaction, and also promote supply-side reform in logistics industry or circulation field, to make coordinated development of local economy.

Resource shortage, environmental degradation and regional protectionism, make the multi-modal transport operation and management face trade-off in economic, ecological and social performance (R. StrulakWójcikiewicz and J. Lemke, 2019 ${ }^{[5]}$. The practice of green transport has become an inevitable choice for balancing those problems. This paper analyzes how to reasonably choose the proportions and weights of transportation modes to satisfy the regional contributions and social requirements, and constructs the optimal transportation mode decision model based on the regional green preference.

\section{Selection of sustainable indicators for multi-model transport}

\subsection{Environmental performance: introduction of carbon emission Index}

The carbon emissions can be calculated by the energy consumption model (T.Y. Jiang etc., 2019) ${ }^{[6]}$. The IPCC Guidelines for Energy Sector Inventories suggest a way to calculate carbon emissions using fuel consumption.

\footnotetext{
a Corresponding author: songzuoling@163.com, songzuoling@sdust.edu.cn
} 
This is a top-down calculation method, which needs to calculate carbon dioxide according to the fuel consumption data of transportation vehicles. The specific calculation formula is as follows:

$$
C_{a}=\sum X_{a b} \cdot P_{b}
$$

$C_{a}$ represents the carbon emissions generated by transportation mode $a ; X_{a b}$ represents the fuel consumption when transport mode $a$ uses fuel type $b$ whose unit is $\mathrm{kg} ; P_{b}$ represents the carbon dioxide emission coefficient of fuel $b$ whose unit is $\mathrm{kg}-\mathrm{CO}_{2} / \mathrm{kg}$, that is the carbon dioxide emission per fuel $b$ consumed.

Furthermore, $P_{b}$ is carbon dioxide emission coefficient, and its calculation formula is as follows:

$$
P_{b}=M_{b} \bullet e P_{b}
$$

$\mathrm{M}_{b}$ represents the net calorific value $(\mathrm{TJ} / \mathrm{Gg})$ of fuel $b$, that is, the heat released by burning one kilogram fuel $b$;

$e P_{b}$ represents the carbon emission factor $(\mathrm{kg}-\mathrm{CO} 2 / \mathrm{TJ})$ of fuel $b$, namely, the carbon emission generated by burning one kilogram of fuel $b$.

Given that the fuels for road, railway and waterways transport include gasoline, diesel and coal. Refer to the IPCC guidelines, the values of $M_{b}, e P_{b}$ of various fuels are shown in Table 1, so carbon dioxide emission coefficient $P_{b}$ can be obtained by using Equation 2 as follows.

Table1. Parameter setting for different fuels

\begin{tabular}{|c|c|c|c|c|}
\hline $\begin{array}{c}\text { Transportat } \\
\text { ion mode }\end{array}$ & Fuel & $\begin{array}{c}\mathrm{M}_{b} \\
(\mathrm{TJ} / \mathrm{Gg})\end{array}$ & $\begin{array}{c}e P_{b} \\
(\mathrm{~kg} / \mathrm{TJ})\end{array}$ & $P_{b}$ \\
\hline $\begin{array}{c}\text { Road } \\
\text { transport }\end{array}$ & gasoline & 43 & 69300 & 2.9799 \\
\hline $\begin{array}{c}\text { Railway } \\
\text { transport }\end{array}$ & diesel & 43 & 69300 & 2.9799 \\
\hline $\begin{array}{c}\text { Maritime } \\
\text { transport }\end{array}$ & coal & 28.2 & 107000 & 3.0174 \\
\hline
\end{tabular}

\subsection{Social performance index: introduction of regional transport infrastructure utilization}

The social dimension is essential to sustainable development together with the economic and environmental aspects. There is an additional treatment to estimate the contribution to the social sustainability of infrastructure projects under conditions of uncertainty (L. A. Sierra etc., 2017) ${ }^{[7]}$.

The construction, operation and maintenance of transportation infrastructure require huge investment of manpower and materials, thus bring a large number of employment opportunities for local region. Regional employment improvement can be described as the working year of a person created by one million yuan of traffic investments, and is equivalent to regional transport infrastructure utilization index. Regional transport infrastructure utilization represented by symbol $\eta$, and the specific calculation formula is as follows:

$$
\eta=\frac{\omega_{N}}{\beta_{Y}}
$$

$\omega_{N}$ represents the total number of employees' working time created by traffic infrastructure investment (unit: year); $\beta_{Y}$ represents total investment amount in transport system (unit: million).

\section{Model construction of sustainable multi-model transport}

\subsection{Establish the initial multi-objective optimization model}

The multi-modal transport routing model in low-carbon environment has multiple dimensions, which not only considers profits of enterprises, but also considers environmental criteria, and at the same time, incorporates social performance of transportation system application. This paper proposes a multi-objective decision-making model with the least carbon emission, the lowest freight cost and the greatest social contribution to pursuit optimal performance of sustainable aspects.

\subsubsection{Assumptions}

When analyze the operation of MMT, the main asumptions are as follows:

- The same batch of goods cannot be converted many times at one intermediate node;

- The same batch of goods can choose only one kind of transport mode when passing a certain road section;

- During the whole MMT process, the freight volume remains unchanged, taking the container load as the basic transport unit.

According to the statistics from China economy website, the base prices of the three modes of transportation are also shown in Table 2. The energy consumption of fuels is different. When transport one ton goods per kilometre, it will consume $0.509 \mathrm{~kg}$ gasoline, $0.00259 \mathrm{~kg}$ diesel, $0.0117 \mathrm{~kg}$ coal (L. Lin, 2009) ${ }^{[8]}$. Combining the carbon emission coefficient $P_{b}$ in Table 1 , the carbon emissions of the three transportation modes in terms of unit cargo turnover can be calculated as shown in Table 2.

Table2. Characters of each transport mode

\begin{tabular}{|c|c|c|}
\hline $\begin{array}{c}\text { Transportation } \\
\text { mode }\end{array}$ & $\begin{array}{c}\text { Transportation } \\
\text { costs } \\
\text { (yuan } / \mathrm{t} \cdot \mathrm{km} \text { ) }\end{array}$ & $\begin{array}{c}\text { Carbon } \\
\text { emissions } \\
(\mathrm{kg} / \mathrm{t} \cdot \mathrm{km})\end{array}$ \\
\hline Road transport & 0.34 & 0.1517 \\
\hline Railway transport & 0.25 & 0.0077 \\
\hline Maritime transport & 0.15 & 0.0368 \\
\hline
\end{tabular}

Based on actual investigation and reference to literatures (A. Falzarano, 2008) ${ }^{[9]}$, the resulting data are shown in Table 3.

Table3. Transfer costs (yuan/TEU) and carbon emissions $(\mathrm{kg} / \mathrm{t})$

\begin{tabular}{|c|c|c|c|}
\hline & Railway & Road & Maritime \\
\hline Railway & $/$ & $30 / 3.24$ & $50 / 4.234$ \\
\hline Road & $30 / 3.24$ & $/$ & $30 / 4.28$ \\
\hline Maritime & $50 / 4.234$ & $30 / 4.28$ & $/$ \\
\hline
\end{tabular}




\subsubsection{Decision Variables}

There are two types of decision variables to describe strategies on choosing transport modes, which are shown in Equation (4) and (5).

$$
\begin{aligned}
x_{i j}^{k} & = \begin{cases}1 & \text { There is a freight used transport mode } k \text { between } v_{i} \text { and } v_{j} \\
0 & \text { There is no reight used transport mode } k \text { between } v_{i} \text { and } v_{j}\end{cases} \\
y_{i}^{k l} & = \begin{cases}1 & \text { There is transfer from tranport mode } k \text { to } l \text { at } v_{i} \\
0 & \text { There is no transfer from tranport mode } k \text { to } l \text { at } v_{i}\end{cases}
\end{aligned}
$$

\subsubsection{The objective function}

The objective function is to optimize performance of economy, environment, and society.

$$
\begin{gathered}
Z_{p}=\min \sum_{i \in v} \sum_{j \in v} \sum_{k \in K} C_{i j}^{k} \cdot d_{i j}^{k} \cdot x_{i j}^{k} \cdot m+\sum_{i \in v} \sum_{j \in v} \sum_{k \in K} c_{i}^{k l} \cdot y_{i}^{k l} \cdot m \\
Z_{e}=\min \sum_{i \in v} \sum_{j \in v} \sum_{k \in K} S_{i j}^{k} \cdot d_{i j}^{k} \cdot x_{i j}^{k} \cdot m+\sum_{i \in v} \sum_{j \in v} \sum_{k \in K} s_{i}^{k l} \cdot y_{i}^{k l} \cdot m \\
Z_{s}=\max \sum_{i=1}^{n} \eta_{i}
\end{gathered}
$$

Equation (6), $Z_{p}$ namely profit objective, is to minimize the transportation costs, which include freight costs between nodes and transfer costs inside nodes. $k$ represents the transportation mode $k=\left\{k_{1}, k_{2}, k_{3}\right\}$, which stand for roads, railways and waterways respectively, $m$ represents freight volume, $C_{i j}^{k}$ represents freight cost between $v_{i}$ and $v_{j}$ used transport mode $k, d_{i j}^{k}$ represents transport distance between $v_{i}$ and $v_{j}$ used transport mode $k$, $x_{i j}^{k}$ represents whether there is a freight used transport mode $k$ between $v_{i}$ and $v_{j}, c_{i}^{k l}$ represents transfer cost when switching from transport mode $k$ to mode $l$ at the node $v_{i}, y_{i}^{k l}$ represents whether there is transfer from transport mode $k$ to $l$ at $v_{i}$.

Equation (7), $Z_{e}$ namely environmental objective, is to minimize the total carbon emissions, which include the carbon emissions consumed between nodes and the carbon emissions consumed by conversion of transportation modes inside nodes. $S_{i j}^{k}$ represents carbon dioxide emissions between $v_{i}$ and $v_{j}$ used transport mode $k$, $s_{i}^{k l}$ represents carbon dioxide emissions when switching from transport mode $k$ to mode $l$ at the node $v_{i}$,

Equation (8), $Z_{s}$ namely social objective, is to maximize the regional transport infrastructure to realize greatest social benefits. $\eta_{i}$ represents regional transport infrastructure utilization at the node $v_{i}$.

\subsubsection{Constraints}

$$
\begin{gathered}
\sum_{k \in K} x_{i j}^{k}=1 \quad(i, j=1,2, \cdots n) \\
\sum_{k \in K} \sum_{l \in K} y_{i}^{k l} \leq 1 \quad(i, j=1,2, \cdots n) \\
\sum_{i \in v} \sum_{j \in v} \sum_{k \in K} T_{i j}^{k} \cdot x_{i j}^{k}+\sum_{i \in v} \sum_{j \in v} \sum_{k \in K} t_{i}^{k l} \cdot y_{i}^{k l} \leq T_{0} \\
x_{i j}^{l}=y_{i}^{k l}(i, j=1,2, \ldots, n ; k, l \in K)
\end{gathered}
$$

$$
\begin{aligned}
& m \leq m_{i}^{k l} \quad(i, j=1,2, \cdots n ; k \in K) \\
& x_{i j}^{k}, y_{i}^{k l} \in\{0,1\}
\end{aligned}
$$

Constraint (9) means that only one kind of transport mode can be selected between determined node $v_{i}$ and $v_{j}$;

Constraint (10) means that at the node $v_{i}$ change of transport mode can only be carried out once, otherwise there is no transfer of mode;

Constraint (11) indicates that the goods must be delivered within the specified time, and the whole time includes the transport time between two nodes and the transfer time inside the nodes. $T_{0}$ represents the time limit of the goods transport:

Constraint (12) ensures the consistency of process consisting of transport mode in the interval of two adjacent nodes and transfer within the two adjacent nodes. In another word, from node $v_{i}$ to node $v_{j}$, if change from transport mode $k$ to mode $l$ happens in node $v_{i}$, the route from node $v_{i}$ to next node should apply transfer mode $l$. Otherwise interruption will occur.

Constraint (13) ensures that the freight volume cannot exceed the maximum volume of transport mode $k$.

Constraint (14) limits decision variables to be true or false.

\subsection{Balance objectives by regional green preference}

When solving multi-objective optimization models, linear weighting method is generally used to transform multiobjective linear programming into single-objective linear programming, which is conducive to obtaining the optimal solution for each objective at the same time.

In order to balance three aspects, this paper proposes the regional green preference as the weight of sustainable goals. The improved optimization model is as follows:

$$
\min Z=\min \left(\sum_{i=1}^{3} \lambda_{i} f_{i}\right)
$$

In above equation, $\lambda_{i}$ is the weight of the function, and its value is between 0 and 1 . Different optimal solutions can be obtained by improving the model with different weights.

As transport costs, carbon emissions and social contributions are of different importance in the optimal routing planning of MMT, they are divided into different levels, as shown in Table 4 . The greater the sensitivity value is, the greater the related weight is.

Table 4. Green preference degree division

\begin{tabular}{|c|c|c|c|}
\hline $\begin{array}{c}\text { Green preference } \\
\text { degree } \lambda_{i}\end{array}$ & Strong & General & Weak \\
\hline Value & 0.5 & 0.3 & 0.2 \\
\hline
\end{tabular}

\section{Solution by poly-population genetic algorithm}

Since there are many variables involved in the above optimization model, the objective function needs to obtain an optimal solution in the end, so genetic algorithm is more suitable. The main reason of limitation 
for simple genetic algorithm (SGA) running into local optimum is loss of diversity in the population. So it's an effective way to explore a new search domain by maintaining the population diversity continuously during the evolution process (L. Wei and M. Zhao, 2005) ${ }^{[10]}$. This paper applies a ploy-population genetic algorithm aiming to enhance and maintain the diversity of populations.

Simple genetic algorithm includes the following steps: encoding and decoding, initialization of population, construction of fitness function, selection, mutation and crossover operation, and get the final result by setting convergence condition. The MMT optimization model uses the poly-population genetic algorithm by adding reinsertion operation and migration operation in solving process, and finally selects the optimal results through reserving elite strategy.

Reinsertion operation: Reinsertion completes the insertion of children into the current population, replaces the parent with children, and returns to the next generation.

$$
P_{l}=\left(P_{l}^{1}, P_{l}^{2}, \ldots, P_{l}^{N-N^{*}}, P_{l}^{1}, P_{l}^{2}, \ldots, P_{l}^{N^{*}}\right) \quad(l=1,2, \ldots M)
$$

In the formula, $P_{l}^{1}, P_{l}^{2}, \ldots, P_{l}^{N-N^{*}}$ are the $N-N^{*}$ individuals with the highest fitness in the parent generation; $P_{l}^{1}, P_{l}^{2}, \ldots, P_{l}^{N^{*}}$ are $N^{*}$ individuals after cross and mutation operation for the set of selected individuals.

Immigration operation: The optimal individual produced in each iteration will appear in other population in next iteration, realizing information exchange between different populations, achieving coevolution of polypopulation, and making each population evolve iteratively in the optimal direction.

$$
\begin{aligned}
& P_{1}=\left(P_{1}^{1}, P_{1}^{2}, \ldots, P_{1}^{\zeta}, \ldots, P_{1}^{N}\right)=\left(P_{1}^{1}, P_{1}^{2}, \ldots, P_{M}^{\delta}, \ldots, P_{1}^{N}\right) \\
& P_{l+1}=\left(P_{l+1}^{1}, P_{l+1}^{2}, \ldots, P_{l+1}^{\zeta}, \ldots, P_{l+1}^{N}\right)=\left(P_{l+1}^{1}, P_{l+1}^{2}, \ldots, P_{l}^{\delta}, \ldots, P_{l+1}^{N}\right)
\end{aligned}
$$

Where, $P_{l+1}^{\zeta}$ is the least adaptable individual $\zeta$ in the $l+1$ group; $P_{l}^{\delta}$ is the individual $\delta$ with the highest fitness in the population $l$.

Elite retention converge: The optimal individuals in various groups are selected and stored in the elite population without genetic operation to ensure that the optimal individuals produced by various groups are not destroyed or lost.

$$
\text { genOI } \leq M A X G E N
$$

Where, the variable $M A X G E N$ is the maximum generations for the optimal individuals in the elite population. If the generations genOI maintained by the optimal individual reaches the maximum generations, the entire genetic operation stops.

\section{Case study}

\subsection{Case description}

One third party logistics company carries a batch of goods for the consignor from Nanning to Changchun. The goods are transported from the origin node $A$ to the destination $B$ via $C_{1}, C_{2}, C_{3}, D_{1}, D_{2}$ by MMT. Given that the cargo weighs $60 \mathrm{t}$, the third party logistics company intends to transport it in four containers of TEU. Its transportation network is shown in Figure 1.

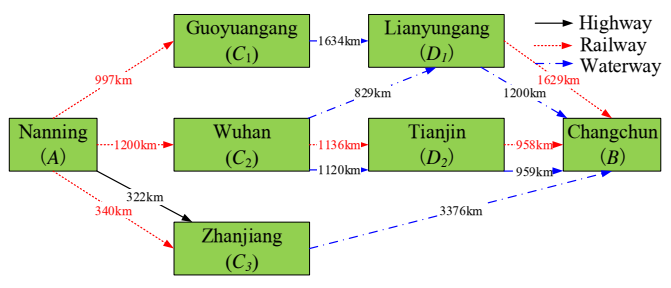

Figure 1. Transport network map

\subsection{Data Analysis}

The transport costs between nodes and the carbon dioxide emissions are calculated using the data in Table 2, as shown in Table 5.

Table 5. Transportation costs (yuan) and carbon emissions (kg)

\begin{tabular}{|c|c|c|c|}
\hline & Highway & Railway & Waterway \\
\hline$A \rightarrow C_{1}$ & - & $14955 / 460.61$ & - \\
\hline$A \rightarrow C_{2}$ & - & $18000 / 554.4$ & - \\
\hline$A \rightarrow C_{3}$ & $6568.8 / 2930.84$ & $5100 / 157.08$ & - \\
\hline$C_{1} \rightarrow D_{1}$ & - & - & $14706 / 3607.9$ \\
\hline$C_{2} \rightarrow D_{1}$ & - & - & $7461 / 1830.4$ \\
\hline$C_{2} \rightarrow D_{2}$ & - & $17040 / 524.8$ & $10080 / 2472.9$ \\
\hline$C_{3} \rightarrow B$ & - & - & $30384 / 7454.2$ \\
\hline$D_{1} \rightarrow B$ & - & $24435 / 752.6$ & $10800 / 2649.6$ \\
\hline$D_{2} \rightarrow B$ & - & $14370 / 442.6$ & $8631 / 2117.5$ \\
\hline
\end{tabular}

This paper takes the container as the transport unit, Using the data in table 3 to calculate the data of the nodes whose transportation mode needs to be changed. The calculated results are shown in Table 6.

Table 6. In-node transfer costs (yuan) / carbon emissions (kg)

\begin{tabular}{|c|c|c|c|}
\hline & changes & costs (yuan) & carbon $(\mathbf{k g})$ \\
\hline$C_{1}$ & Railway $\rightarrow$ Waterway & 200 & 254.04 \\
\hline$C_{2}$ & Railway $\rightarrow$ Waterway & 200 & 254.04 \\
\hline \multirow{2}{*}{$C_{3}$} & Railway $\rightarrow$ Waterway & 200 & 254.04 \\
\cline { 2 - 4 } & Highway $\rightarrow$ Waterway & 120 & 256.80 \\
\hline$D_{1}$ & Railway $\rightarrow$ Waterway & 200 & 254.04 \\
\hline$D_{2}$ & Railway $\rightarrow$ Waterway & 200 & 254.04 \\
\hline
\end{tabular}

For each transport node, the employees' working time created by traffic infrastructure investment and the total investment amount are shown in Table 7.

Table 7. Transportation infrastructure utilization(year/million)

\begin{tabular}{|c|c|c|c|c|c|c|c|}
\hline Facilities & $A$ & $C_{1}$ & $C_{2}$ & $C_{3}$ & $D_{1}$ & $D_{2}$ & $B$ \\
\hline Work time & 607 & 1000 & 3000 & 1440 & 2950 & 1072 & 1800 \\
\hline Investment & 1680 & 2258 & 6227 & 2848 & 4300 & 1500 & 3210 \\
\hline
\end{tabular}

\subsection{Computational Results}

The above model of MMT based on green preference degree is optimized by MATLAB software. The results 
obtained by the improved PPGA and the SGA are shown in Figure 2.

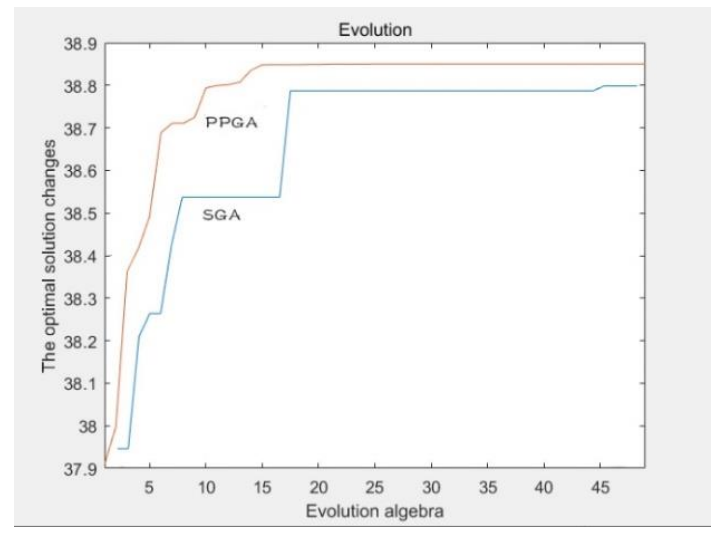

Figure 2. Comparison of two algorithms

The PPGA is more stable and begins to converge after about 10 generations. The optimal transport routing scheme is $\mathrm{A} \rightarrow \mathrm{C}_{2} \rightarrow \mathrm{D}_{1} \rightarrow \mathrm{B}$, from Nanning to Wuhan by railway, and from Wuhan to Lianyungang then to Changchun by waterway.

The optimal cost is 36661 yuan, the optimal carbon emission is $5542.48 \mathrm{~kg}$, and the optimal regional transportation infrastructure utilization is 2.1 year/million.

\section{Conclusions}

This paper conducted standardized accounting of carbon emissions for different transport modes, and introduced environmental and social performance objectives, to balance economic, environmental and social goals, and built a dynamic decision-making model of sustainable multi-modal transportation. This paper proposed polypopulation genetic algorithm from the perspective of enhancing and maintaining the diversity of populations, and was proved to achieve faster convergence and better optimum, and finally got optimal multi-modal transport scheme based on regional green preference degree.

This model and solution will provide quantitative decision support for the third party logistics companies, international freight forwarders, to carry out the green or sustainable multi-modal transport.

For the future research, differences between domestic and foreign transportation, such as fuel price, currency or tax changes could be also taken into account. Moreover, intelligent algorithms need to be combined to achieve high-efficiency search and convergence abilities when solving multi-objective optimization.

\section{Acknowledgement}

We are sincerely grateful to editor and other reviewers' critical comments and suggestions.

Funding: the authors would like to acknowledge the Qingdao Social Science Planning Project (Grant number: QDSKL2001118).

\section{References}

1. B. Lv, B. Yang, X. Zhu, J. Li, Operational optimization of transit consolidation in multimodal transport, Comput. Ind. Eng. 129, 454-464 ( 2019)

2. Y. Wang, G. Yeo, A study on international multimodal transport networks from Korea to Central Asia: Focus on secondhand vehicles, ASIAN. J. Shipp. Logis. 32, 1, 41-47(2016)

3. M. Salehi, M. Jalalian, M. M. Vali Siar, Green transportation scheduling with speed control: Tradeoff between total transportation cost and carbon emission, Comput. Ind. Eng. 113, 392-404( 2017)

4. B. Lin, N. I. Benjamin, Influencing factors on carbon emissions in China transport industry: A new evidence from quantile regression analysis, J. Clean. Prod. 150, 175-187(2017)

5. R. Strulak-Wójcikiewicz, J. Lemke, Concept of a simulation model for assessing the sustainable development of urban transport, Transport. Res. Procedia 39, 502-513( 2019)

6. T. Jiang, S.J. Huang, J. Yang, Structural carbon emissions from industry and energy systems in China: An input-output analysis, J. Clean. Prod. 240, 113(2019)

7. L. A. Sierra, V. Yepes, E. Pellicer, Assessing the social sustainability contribution of an infrastructure project under conditions of uncertainty, Environ. Impact. Asses. 67, 61-72( 2017)

8. L. Lin. Railway: the Pride of Green transportation. Railw. Knowl. 2, 4-11(2009)

9. A. Falzarano. An evaluation of energy consumption and emissions from intermodal freight operations on the Eastern Seaboard: A GIS network analysis approach. Dissertations \& Theses Gradworks(2008)

10. L. Wei, M. Zhao, A niche hybrid genetic algorithm for global optimization of continuous multimodal functions, Appl. Math. Compu. 160,3, 649661(2005) 